\title{
HERRERA Y PONTANO: LA MÉTRICA EN LAS 'ANOTACIONES
}

Se ha dicho muchas veces que Herrera no se ocupa en sus Anotaciones a Garcilaso de aspectos métricos. Lo señala Coster, con su rígido criterio de clasicista francés, y lo repite Bianchini ${ }^{1}$. En realidad es una afirmación sólo parcialmente cierta. Herrera sí trata de cuestiones métricas, o por lo menos de ciertas cuestiones. No atiende, o sólo de pasada, a puntos como la rima, el número de sílabas, acentos o cesuras, pero sí tiene muy en cuenta otros aspectos que atañen a la métrica: eufonía y cacofonía, colorido vocálico, sinalefa y dialefa, diéresis y sinéresis, aliteración; y, en relación con todo ello, el orden de las palabras. Es un hecho conocido de cualquier lector de las Anotaciones herrerianas.

Un comentario no es un tratado sistemático, y Herrera no tiene por qué ofrecer una teoría métrica exhaustiva. Sin embargo, creo que se puede encontrar alguna explicación o explicaciones que justifiquen el enfoque y la selección de observaciones métricas de nuestro poeta. Son razones de dos tipos que inevitablemente se entrecruzan: razones lingüístico-métricas y razones históricas.

La nueva poesía italianizante se basa en una relación perfectamente acorde entre "modelo de verso" y prosodia de la lengua standard". Los acentos prosódicos y rítmicos coinciden, $\mathrm{y}$, si se da alguna tensión, es realmente muy secundaria. Herrera nos lo dice al principio de las Anotaciones: "porque en nuestra lengua... demás de los pies, que más por naturaleza que por alguna regla es necesario guardar en los versos..." ${ }^{3}$ Para Herrera, el ritmo del hendecasílabo es un hecho natural que coincide con el de la lengua cotidiana, y por ello no

1 A. Coster, Fernando de Herrera (el Divino), 1534-1597, Paris, 1908, pp. 395-397; A. Bianchinl, "Fernando de Herrera's Anotaciones: A new look at his sources and the significance of his poetics", $R F, 88$ (1976), p. 41; véase también J. AlmEIDA, La critica literaria de Fernando de Herrera, Madrid, 1976, pp. 94-95.

${ }^{2}$ Cf. F. LÁzAro, "La poética del arte mayor", en sus Estudios de poética, Madrid, 1976, p 82

${ }^{3}$ Cito por la edición de A. Gallego Morell, Garcilaso de la Vega y sus comentaristas, Madrid, 1972. Esta primera cita (H-1) está en las pp. 308-309. 
necesita "regla", no está sujeto a artificio ${ }^{4}$. Por eso Herrera no tiene en cuenta el ritmo del hendecasílabo (excepto en un caso, y es justamente un verso italiano de Anguillara) ${ }^{5}$. No le parece un dato relevante porque considera el ritmo como algo natural que no crea ruptura con la lengua. En el prólogo, Pedro de Medina insiste sobre esta idea: " $\mathrm{Al}$ fin, viendo [Herrera] que nuestros razonamientos ordinariamente discurrían sin armonía, nos enseñó con su ejemplo cómo, sin hacer violencia a las palabras, las torciésemos blandamente a la suavidad de los números"6. La lengua cotidiana pasa naturalmente, "sin violencia", "blandamente", a encarnar el verso. Hay en todo esto un esfuerzo por insertar a la poesía en la sociedad mediante una poética abierta por la base. Frente al mundo cerrado y la poética cerrada medieval, la poética renacentista busca a través de la lengua una simbiosis parcial con un mundo que empieza a abrirse.

Por otra parte, el concepto de metro o número en Herrera es más amplio de lo que se contiene en un tratado de métrica tradicional. Es un concepto similar al que pudo encontrar en Pontano o Escalígero. Dice éste en su Poética: "Numerus est conveniens sententiae sonus ex compositione et dispositione partium. Compositionem appello verborum ex elementis et syllabis, ac membrorum ex verbis. Dispositionem rationem modumque compositionis. Oportet enim verba et esse talia et tali ordine collocata" . Conviene traducirlo: "El número es el sonido acorde a un pensamiento producido por la $\ll$ compositio $\gg$ y $\ll$ dispositio $\gg$ de sus partes. Llamo $\ll$ compositio $\gg$ de las palabras a la que surge de sus elementos y sílabas, $\mathrm{y} \ll c o m p o s i t i o \gg$ de los miembros a la que surge de las palabras. La «dispositio $\gg$ es el orden y modo de la $\ll$ compositio $\gg$. Es necesario, pues, que las palabras sean de una naturaleza determinada y estén colocadas en un orden específico". No es solamente la sucesión de pedes lo que caracteriza al numerus, sino que éste abarca también la calidad de las palabras, sus fonemas y sílabas, y su ordenación. Pontano, por su parte, no da en el Actius una definición de numerus - iría contra la naturaleza del diálogo y del propio autor-, pero implícitamente utiliza también un concepto amplio en el que incluye, como veremos después, otras muchas cosas además del ritmo. Herrera se coloca en esta misma línea y utiliza el término "número" con valores complejos: unas veces como número de sílabas, pero en otros casos "número" significa calidad de las palabras, como en H-732 (p. 559): “Áspero número es cuando se juntan palabras de

\footnotetext{
${ }^{4}$ No sé si es casualidad el que en poética española no se marque de forma precisa la diferencia entre acento prosódico y acento rítmico hasta 1626; cf. A. García Berrio. Introducción a la poética clasicista: Cascales, Barcelona, 1975, p. 224.

s Lo señala Coster, op. cit., p. 396.

- "El maestro Francisco de Medina a los lectores", en A. Porqueras Mayo, El prólogo en el Renacimiento español, Madrid, 1965, p. 222.

7 J.C. Scaligeri, Poetices libri septem, Heidelberg, 1617, p. 411 (IV, 1).
} 
tres o cuatro consonantes", o en H-31 (p. 323): "la pesadumbre de la contextura, dicciones y número". Seguramente Herrera estaría de acuerdo con una definición como la de Shapiro-Beum: "El metro debería definirse como el esquema recurrente -teóricamente regular, aunque en la práctica a veces muy vario-de los detalles acústicos que figuran en el interior del verso"8. Rima y número son sólo uno de los detalles, el más monótono, como se ha señalado muchas veces ${ }^{9}$. Y justamente lo que hace rítmico a un verso son todos los otros detalles; como dice Herrera comentando un caso de dialefa (H-93, p. 349), "estas divisiones hechas artificiosamente dan grande resplandor a la poesía y la retiran de la comunidad de los que sólo hacen versos". Herrera realiza una selección de las características del verso ga rcilasiano y, evidentemente, lo que subraya son los rasgos que lo hacen "admirable" y los aspectos más difícilmente codificables del verso. Es una postura aristocrática que no se rebaja a lo más fácil. Justamente no sé si es casualidad el que las dos únicas observaciones sobre rima las ponga en boca de Francisco de Medina, como si él mismo no quisiera comprometerse con estas cosas ${ }^{10}$.

El humanismo literario parte de un concepto peculiar del fenómeno poético como fenómeno retórico, o, dicho de otro modo, de la unidad entre prosa y poesía. "Mihi semper placuit carmen quod a prosa, sed optima, non longe recederet... Me vehementer delectat poema rhetoricum et rhetor poeticus, ut et in oratione soluta carmen agnoscas et in carmine rhetoricam phrasin", nos dice Erasmo ${ }^{11}$. Y, más tajantemente, Pedro de Valencia, citand o el De compositione verborum de Dionisio de Halicarnaso (obra que Herrera conocía muy bien ${ }^{12}$ ): "que no hay tal

${ }^{8}$ K. Shapiro-R. Beum, “Metro, ritmo, espressivitä", en R. Cremante-M. Pazzaglia, La metrica, Bologna, 1972, p. 112.

${ }_{9}$ Cf. ibid., p. 113; J. CohEn, Estructura del lenguaje poético, Madrid, 1974, pp. 50 ss.; Tomachevsk1, "Sobre el verso", en T. Todorov; Teoria de la literatura de los formalistas rusos, Buenos Aires, 1970, p. 124.

${ }_{10}$ H-627 (p. 530) y H-654 (p. 535). En este último caso se trata de la rima interna "silvanos" con "faunos"( Égloga II, 1 156-1157). Aquí Herrera intenta dar también una explicación de esta rima como "verso procelio o ventroso, cuando sobra en medio o sílaba o tiempo", pero acaba con cierta ironía: "si esto no satisface, podrá servir hasta que haya otra cosa que excuse la demasía de la licencia". Pienso que en esta rima se trata de lo que C. Di Girolamo llama "verso per l'occhio" (Teoria e prassi della versificazione, Bologna, 1976, pp. 93-97). Es un aspecto de la poesía garcilasiana que merecería estudio.

11 "Me ha.agradado siempre el poema que no se aparta mucho de la prosa, siempre que ésta sea buena... Me deleita sobremanera el poema retórico y el retor poético, de forma que se reconozca la poesía en el discurso en prosa y la elocución retórica en el poema": Epistulae, 112, citado por E. Norden, Die antike Kunstprosa, 6a ed., Stuttgart, 1971, t. 2, p. 904, junto con otras referencias similares.

12 Lo aprovecha varias veces explícitamente y otras veces sin citarlo, como es habitual en él (véase también R.M. BEACH, Was Fernando de Herrera a Greek scholar?, Philadelphia, 1908, p. 41); naturalmente podía leerlo en latín en la traducción de Stanislaus Ilovius, Dionısii Halicarnasseinonnulla opuscula. . , París, 1556. 
prosa como la que parece verso, ni tal verso como el que parece prosa" $"$. Herrera participa de estas ideas, y por eso analiza a Garcilaso como un texto retórico y le aplica la taxonomía de la elocutio. Por ese motivo también le interesan poco los aspectos que caracterizan superficialmente al verso, y, en cambio, subraya más los aspectos que el verso comparte con la prosa. Los análisis del Actius de Pontano podían servirle de ejemplo cuando el famoso umbro intercala retazos de prosa ciceroniana junto a versos virgilianos para ejemplificar el mismo fenómeno.

La postura humanística se caracteriza también por el rechazo de la rima, que según un humanista inglés, William Webbe, era invención de los hunos. El rechazo se hacía extensivo al número fijo de sílabas de la poesía romance ${ }^{14}$. En España, desde Nebrija se pueden ir detectando manifestaciones de este rechazo a lo largo de toda la andadura del humanismo peninsular, como ha señalado recientemente Francisco Rico $^{15}$. Junto a este rechazo a parece entre los poetas italianizantes la tendencia a hacer conformar el hendecasílabo castellano al verso latino. El hexámetro latino, el verso heroico equiparable al hendecasílabo, es, según lo entendían los humanistas, resultado de la tensión entre un modelo de verso de pies acentuales dactilicos y espondaicos y una prosodia considerada también como acentual ${ }^{16}$. Las rupturas que se producen en el ritmo del hexámetro son más parecidas a las del verso de arte mayor ${ }^{17}$ que a las del hendecasílabo. Pero los poetas italianizantes no buscaban una equiparación matemática sino una equiparación de efectos auditivos o gráficos. Concretamente, Herrera intenta resaltar en Garcilaso los efectos fónicos que lo hacen comparable al modelo virgiliano. Y por eso también pone en un segundo plano todo lo que se refiere a las nefandas rimas y números.

Es sintomático, o quizá obvio, que Herrera pusiera una especial atención en la forma de análisis de versos virgilianos que desarrolla

13 Pedro de Valencia, "Carta escrita a don Luis Góngora en censura de sus poesías", en A. Martinez Arancón, La batalla en torno a Góngora, Barcelona, 1978, p. 5.

${ }^{14}$ Cf. E. Norden, op. cit., t. 2, pp. 869-870, donde se recogen otros materiales sobre el tema.

${ }^{15}$ F. Rico, "El destierro del verso agudo (con una nota sobre rimas y razones en la poesía del Renacimiento)", en $H J M B$, Madrid, 1983.

${ }^{16}$ Cf. G. Martellotti, "Critica e metrica del Salutati e del Pontano", en Critica e storia letteraria. Studi offerti a Mario Fubini, Padova, 1970, pp. 352-353; debo agradecer a F. Rico que me proporcionara este trabajo fundamental de Martellotti y me sugiriera una posible relación entre Herrera y Pontano.

${ }^{17}$ Cf. F. Lázaro, "La poética del arte mayor", loe. cit. 
Pontano en el diálogo Actius. Se trata de uno de los textos más fínos de crítica renacentista ${ }^{18}$. En síntesis, el Actius trata en su parte central sobre la conjunción de significado y procedimientos formales que hace que un verso sea admirable. Es el dominio del numerus, como se indica en la propositio de esta parte del diálogo ${ }^{19}$. Para ello se va pasando revista a los efectos que producen dialefa y sinalefa, eufonía, semantización del ritmo, ruptura de ritmo y prosodia, relación entre volumen de las palabras y ritmo, los diversos tipos de aliteración, el orden de las palabras (que naturalmente lo domina todo), así como los muchos casos en que se superponen varios de estos procedimientos. La crítica herreriana se asimila naturalmente a la sensibilidad de Pontano. Es el tipo de observaciones que a él le interesa hacer, y que le permiten explicar el hendecasílabo garcilasiano como algo nuevo, complejo y único, semejante a los venerables versos del mantuano. Veamos algunos de los pasajes en que Herrera utiliza más "literalmente" materiales del Actius.

Un rasgo característico de la poética herreriana en su amoralismo o hedonismo. Texto fundamental en ese sentido es un famoso pasaje del discurso sobre la elegía (H-271, p. 420) en el que pone como fin de la poesía producir únicamente "admiración". En realidad lo que está haciendo Herrera en ese punto es comentar y hacer suyo un pasaje de Pontano:

18 Justamente un contemporáneo, Paolo Cor tesi, detine a Pontano como el primer hombre moderno que supo entender la riqueza del numerus poético: "cognita primum numerorum varietas a Pontano", cf. su De hominibus doctis dialogus, ed. M. T. Graziosi, Roma, 1973, p. 46, citado por G. PAREntI, “Pontano o dell' allitterazione: lettura di 'Parthenopeus' 1, 7", Rinascimiento, 15 (1975), p. 90. Pontano tuvo una temprana presencia en.España, pues ya en 1498, en Barcelona, se edita una recopilación de himnos religiosos suyos, el Liber Joviani Pontani Umbri de divinis laudibus; es conocida también la incidencia del Charon en el Mercurio y Carón de Alfonso de Valdés: el. J. F. Montesinos, "Algunas notas sobre el Diálogo de Mercurio y Carón", RFE, 16 (1929), 239 ss.; pero el prestigio de Pontano y concretamente del Actius (a veces no leído directa mente, sino a través del Naugerius de Fracastoro o el De poeta de Minturno) se da ligado a la teoría literaria. Esta línea empieza con Herrera, que lo valora a tal punto que cuando habla de Nápoles dice: (H-365, p. 460) "antiguamente ilustre con el túmulo de Virgilio y hoy con las cenizas de Pontano", y, como intento mostrar, lo utiliza ampliamente en su obra. Juan de la Cueva lo cita en su Ejemplar poético (1606), en la nómina de críticos más importantes: "Vida el norte, Pontano el ornamento" (ed. F. A. de Icaza, Madrid, 1965, p. 147). Vuelve a a parecer en El librode la erudición poética (1611) de LuIS CARRILlo y Sotomayor, con una cita extraña: “Dígalo Pontano sobre Virgilio, capit. 7", que por lo que dice seguramente se refiere al Actius (ed. M. Cardenal Iracheta, Madrid, 1946, p. 39). Por último lo encuentro muy utilizado, sintomáticamente, por un defensor de Góngora, Pedro Díaz DE Ribas, en sus Discursos apologéticos por el estilo del "Polifemo" $y$ "Soledades"(en A. MAR Tínez, La batalla en torno a Góngora, pp. 128, 130, 142 y 145). Ponta no le ofrecía argumentos para defender el amoralismo de la poesía, la libertad de la creación poética frente al vulgo, el formalismo, etc., puntos fundamentales de la poética gongorina que enlazan con el anciano umbro.

19 G. Pontano, I dialoghi, ed. C. Previtera, Firenze, 1943, p. 146, lín. 21-22. 
[Pontanum] saepius audivi poetae sive officium esse dicere apposite ad admirationem; nihil autem nisi excellens admodum parit admirationem.

Numerus autem ipse cum primis et movet et delectat et admirationem gignit.

Omnino poeticus numerus carminis ipsius structuram sequitur, structura vero ipsa constat e dictionibus...

Eius autem prima illa est quod varietatem parit, cuius natura ipsa videtur fuisse vel in primis studiosa. Quid enim vel inertius vel, ut ita dixerim, oscitantius quam eodem semper sono ac tenore syllabas et verba compangere? $?^{20}$
Mas pues el poeta tiene por fin decir compuestamente para admirar, y no intenta sino decir admirablemente, y ninguna cosa sino la muy excelente causa admiración, bien podremos enriquecer los conceptos amorosos en alguna manera de aquella maravilla que quieren los antiguos maestros de escribir bien que tenga la poesía; que si no es excelente, no la puede engendrar, y de ella procede la jocundidad. Verdad es que el número mueve y deleita y causa la admiración; pero nace el número de la frasis, porque sigue el número poético a la estructura del verso, y ésta consta de las dicciones. Yes el primer loor suyo parir variedad, de que es muy estudiosa la naturaleza misma. ¿Qué cosa hay más sin arte y sin juicio, y que con más importuna molestia canse las orejas, que oyen, que trabar silabas y palabras siempre con un sonido $y$ tenor?

El concepto de admiratio lo desarrolla más ampliamente Pontano al final del diálogo (p. 233) comparando la figura del poeta y del orador. El orador puede ser mediocre, pero el poeta debe ser excelente por medio de la admiración que debe engendrar e insuflar en el ánimo del oyente o lector (con la salvedad de que no se trata de cualquier lector, sino del lector que sea también poeta). Sólo esto lo elevará a la fama y veneración, a la gloria renacentista. La excelencia del poeta lleva a Pontano a afirmar su supremacía sobre cualquier otro tipo de elocuencia: "quo fit ut omne dicendi genus a poetica manaverit". Pienso que en Herrera es esa misma conciencia de excelencia la que le lleva a defender la norma de los escritores sobre cualquiier otra norma lingüística en su Controversia con "Prete Jacopín"

\footnotetext{
20 "A menudo oí afirmar (a Pontano) que el poeta tiene porfunción o por fin el decir compuestamente para admirar; y ninguna cosa sino la muy excelente causa admiración" (Actius, en I dialoghi, p. 146, lín. 9-13); "Ciertamente el número sobre todo mueve, deleita y causa admiración" (ibid., lín. 24-25); "El número poético sigue totalmente la estructura del verso, pero a su vez la estructura consta de las dicciones..." (p. 162, 24-25); "Y es el primer loor parir variedad, de la que la misma naturaleza parece haber sido especialmente estudiosa. ¿Qué cosa hay más sin arte o, por así decir, más aburrida que trabar sílabas y palabras siempre con un sonido y tenor?" (p. 146, 25-28).

${ }^{21}$ J.M. Asensio, Controversia sobre las "Anotaciones" a las obras de Garcilaso de
} 
El hedonismo de Herrera parte de Pontano y parcialmente de Horacio. Pero el andaluz, en este y en otros pasajes, tiene la habilidad de reinterpretarlo y darle nuevas facetas. Es una actitud muy singular dentro del contexto de la teoría poética española ${ }^{22}$.

El segundo concepto que Herrera pone de relieve es el de numerus. Complementa lo que dijimos antes sobre este término. La admiración, el objetivo primordial, nace del numerus, y éste nace de las dicciones, de su estructura y de los diversos efectos fónicos que producen, o sea de la frasis, de la elocutio, lo que atañe a las palabras trabadas o aisladas. Es una idea más amplia que la de simple metro. Hay que señalar también que Herrera hace una selección del material pontaniano en función de su propia poética. Después de hablar de la estructura y de las dicciones, Pontano se extiende sobre los acentos latinos ${ }^{23}$ Herrera corta justamente en "dicciones" la cita de Pontano porque no le interesa hablar de ese aspecto del numerus. En cambio, sí le importa añadir la aclaración de que el número nace de la frasis. Resalta precisamente lo que el verso tiene en común con la prosa, lo que está sujeto a los artificios de la elocutio.

En un precioso artículo ${ }^{24}$, don José Manuel Blecua resaltaba la sensibilidad de Herrera al comentar un caso de dialefa (H-93, p.349):

De $\mid$ áspera. No colidió G. L. este verso porque deshizo aquella sinalefa o comprensión que los griegos llaman sinéresis, que es colisión o conjunción con vocales casi enemigas una de otra, que no se puedan contraer juntamente, para que el verso no sea hiulco, que dicen los latinos, o laxo por otro nombre, como:

\section{Insulae Ionio in màgno. . .}

Y con esta diéresis denota G. L., apartando aquellas vocales, la aspereza de los miembros y la repugnancia de la transformación. Y sin duda que estas divisiones hechas artificiosamente dan grande resplandor a la poe-

la Vega, Sevilla, 1870, p. 103; cf. A. Alonso. Castellano, español, idioma nacional, $4^{a}$ ed., Buenos Aires, 1968, pp. 64-67.

22 Así lo señala A. García Berrio. Formación de la teoría literaria moderna, 2. Poética manierista. Siglo de Oro, Murcia, 1980, pp. 82-86 y 233-234. Quizá también el hedonismo de Herrera enlace con algún concepto de Escalígero. Expresiones como "apropian el sentido de quien los lee" (p. 418), o "aquella suave hermosura que suspende y arrebata nuestros ánimos con maravillosa violencia" (p. 419), enlazan con la virtud de la efficacia que exige Escalígero en el poeta (ed. cit., III, 24, p. 259): "vis quaedam tum rerum tum verborum quae etiam nolentem propellit ad audiendum" (la capacidad de la poesía de arrebatar violentamente el ánimo del oyente y obligarlo a escuchar).

${ }^{23}$ Pontano, p. 162, 25-27: “...structura vero ipsa constat e dictionibus, dictiones autem accentum constituunt, singulae singulos. Ipsi quoque accentus dictionum ac syliabarum sequuntur tempora".

${ }^{24}$ J.M. Blecua, "La sensibilidad de Fernando de Herrera. Tres notas para su estudio", en Sobre el rigor poético en España y otros ensayos, Barcelona, 1977, pp. 75-82. 
sía, y la retiran de la comunidad de los que sólo hacen versos. Usólas Virgilio en muchos lugares, y particularmente en el $I$ :

Et vera incessu patuit dea, ille ubi matrem.

El mismo Lasso en el Son. 16:

Mas imflctón de aire en solo un día.

Y bien se deja ver que se levantan y hacen más grandes estos versos por causarse aquel hiato de aquellos elementos que no se juntan bien. Y no impide que diga Gerónimo Ruceli que cuando se encuentran dos vocales es, como él escribe, debilísimo y brutísimo el verso, porque él enseño lo que sintió, y no alcanzó más, y no hay para qué reparar en esto, que tan claro es a todos los que tienen alguna pequeña noticia de la arte. Mas aquel verso de la Geórg..

Ter sunt conati imponere Pelio Ossam,

que allí están desatadas la $I$ doblada de conati y imponere, y la $O$ de Pelio y Ossam, aunque son de unas mismas vocales, y que fácilmente se convierten la una en la otra, convienen así para lo que quiere mostrar Virgilio, porque con estas dos distraciones y apartamientos representa mejor la grandeza del monte y la pesadumbre y dificultad de lo que trata. Con esta imitación, para dar a entender casi semejante dificultad y aspereza, osé yo decir:

El yerto hórrido risco, despeñado, y la montaña áspera parece. . .

Las observaciones de Herrera en efecto son muy agudas, pero no parten de la nada. Se apoyan en la noción de collisio de Pontano:

Collisio igitur vocalium, quam et contusionem et concursum a re ipsa vocare possumus... duabus fit modis, cum aut eaedem concurrunt vocales aut cum diversae; ubi eaedem sese collidunt extruditurque e versu altera, ea tum ademptio tum extrusio recte vocatur, non minus fortasse proprie explosio. Ipsum autem concursum Cicero hiatum vocat et vocales ipsas dicit hiare; at cum permanent neque truduntur loco boatum sunt e litteratoribus qui vocaverint, rectius utique complosio vocabitur, quod e resultu geminetur sonus, ut in ilio:

\section{"Ter sunt conati imponere Pelio Ossam"}

Ipse vero resultus longe minor existit cum e diversis fit vocalibus, ut: "Ionio in magno" 25

25 Pontano (p. 158, 21-36): "Así la colisión de vocales que podemos llamar «choque $\gg 0 \ll$ concurso $\gg$ por el fenómeno en sí... es de dos tipos, uno cuando concurren las mismas vocales y otro cuando son distintas; cuando coliden las mismas vocales y se elimina una de ellas del verso. se puede llamar bien $\ll$ privación $\gg 0 \ll$ extrusión $\gg$, y quizá con igual propiedad «explosión». Cicerón llama hiato a este concurso y dice que las 
Herrera aprovecha para su análisis el término de Pontano y también los ejemplos; incluso el "Et vera incessu..." $($ Aen. 1,405$)$ aparece citado también por Pontano con el mismo objeto una página antes $(157,7)$. Herrera utiliza habitualmente el término "colisión" para definir la dialefa, por ejemplo en H-709 (p. 550): "Entre una: las colisiones hacen más nervoso y lleno y ponderoso el verso".

También emplea el término "complosión" en la acepción que da el pasaje pontaniano antes citado, por ejemplo en $\mathrm{H}-806$ (p. 582) o en H-342 (p. 446), en este último caso citando al poeta umbro: "Que acá. Es cacofonia... Fuera de esto es aprobada esta composición, porque Pontano, hombre eruditísimo, pensó que era un cierto género de complosión, el cual no sin suavidad, como él dice, el concurso de aquellas mismas sílabas regala y deleita los oídos, como Oceano nox, fama malum, date tela"26.

Pontano desarrolla ampliamente el tema de la aliteración en el hexámetro (pp. 181-188). Entre otros puntos trata de la aliteración o complosión de vocales: "Ut autem concursus ipse syllabarum delectat propter complosionem earundem litterarum, sic etiam ac multo magis earundem vocalium; quippe cum ex ipsa complosione magna fiat vocalitati accessio"27; y unas líneas más abajo, sobre las consonantes: "subblanditur enim auribus quaedam quasi strepens litterarum inter se sive concursatio sive conflictatio, ac nonnunquam etiam syllabarum; quae vis ipsis potius inest consonantibus quam vocalibus quae syllabas eas ineunt" 28 .

Creo que hay que tener presentes estos textos para entender lo que dice Herrera en $\mathrm{H}-400$ (p. 465):

$Y$ si no lo fabrico. Imitación del Son. 4. Las vocales suenan más dulcemente que las consonantes, y así hacen más blanda la oración y con más lenidad, y no con tanto ruido y estruendo; pero no se niega por eso que se haga más a mplia la oración con los concursos de ellas, porque ninguno

vocales se hienden; cuando permanecen y no se las elimina de su posición son $\varangle$ vocerío $\gg$ según las llaman los gramáticos; de todas formas es mejor llamarlo «complosión», porque se duplica el sonido por la repercusión, por ejemplo en aquel verso: $\ll$ Tres veces intentaron imponer el Osa sobre el Pelión $\gg[G, I, 281]$. Pero la repercusión se da con mucha menor fuerza cuando se encuentran vocales distintas, por ejemplo: «en el magno Jonio». [Aen., III, 211]".

26 Actius, p. 183, 27-29: "Non insuaviter etiam concursus earundem syllabarum mulcet aures; est enim gehus quoddam complosionis: ruit oceano nox, et Fama malum, et Date tela".

${ }_{27}$ Ibid., p. 183, 34, a 184, 3: "En verdad, el concurso de sílabas deleita por la complosión de las mismas letras, pero mucho más si son las mis mas vocales, pues de la complosión nace gran acrecentamiento de la eufonía".

${ }_{28}$ Ibid., p. 184, 11-15: "Acaricia dulcemente los oíd os uno como estruendo de las letras entre sí, o concurso o herimiento, y, a veces, incluso de las sílabas; y esa fuerza recae más en las consonantes que en las vocales que forman esas sílabas". 
hay que no entienda que del frecuente y espeso encuentro de las vocales se compone una oración grande y llena demasiadamente y viciosa. Llámase el concurso o herimiento y colisión de las vocales sinalefa en griego.

Para nosotros esto sería un caso de eufonía o de colorido vocálico. Visto desde el esquema del Actius, es un caso de aliteración vocálica. Por eso Herrera al final dice "Llámase el concurso o herimiento y colisión...", traduciendo términos pontanianos.

Una buena parte de las observaciones de Herrera sobre métrica giran en torno a la distribución de vocales y consonantes en la poesía de Garcilaso. Y, naturalmente, los materiales del Actius vuelven a surgir. Por ejemplo al comentar el verso 10 de la Elegía II, "el humo sube al cielo, el son se escucha" (H-373, p. 462):

El humo. Es sygmatismós, que hay tres $s$ en principio de 3 dicciones. El lugar es de aquel maravilloso verso y lleno de celeridad:

nec se iam capit unda, volat vapor ater ad auras,

donde Virgilio puso otras tres $U$ en principio de 3 dicciones.

Pontano cita justamente ese verso virgiliano (Aen., VII, 466) como ejemplo de aliteración a principio y final de palabra: "quid cum primarum et ultimarum [syllabarum] simul: «volat vapor ater $\gg ?, 2 \overrightarrow{9}$ Herrera subraya ese mismo hecho y lo pone en relación con el fenómeno similar de la $s$ en Garcilaso. Además, Pontano vuelve a utilizar el mismo verso de Virgilio como muestra de conjunción entre aliteración y ritmo. Es un verso repleto de dáctilos, por tanto muy rápido, que alcanza gran volumen, como el agua que se expande y hierve: "Idem ipse Virgilius evaporantis aheni aestum ebullitionemque illam vix sese intra labrum continentis aquae cum explicaret, versum ita dilatavit, vix ut se ipsum capiat, quippe quem decem usque ad accentus extenderit nec habuerit quo amplius: $\varangle \mathrm{Nec}$ iam se capit unda, volat vapor ater ad auras $\gg 30$. Es muy probable que Herrera tuviera en mente ese comentario cuando apunta: "aquel maravilloso verso y lleno de celeridad".

Los versos de Virgilio han sido muy conocidos siempre, y, naturalmente, Herrera no necesitaba una fuente concreta para citar al man-

29 Ibid., p. 185, 1: “QQué efecto se produce cuando hay aliteración al mismo tiempo en las primeras y últimas sílabas: «Vuela el oscuro vapor»?"

30 Ibid., p. 185, 27-31: “El mismo Virgilio al describir el calor del caldero lleno de vapor $y$ aquel hervor del agua que a duras penas se mantiene dentro del recipiente, dilató de tal forma el verso que apenas cabe en sí mismo, y de hecho lo extendió a lo largo de diez palabras hasta el límite de acentos y no tenía con qué más: $\ll y$ el agua ya no cabe en sí, vuela el oscuro vapor por los aires» [Aen., VII, 466]". 
tuano. Pero el tipo de observaciones que hace coincide con las de Pontano, y es entonces cuando la identidad de ejemplos se hace sospechosa.

Herrera intenta en sus Anotaciones algo absolutamente original: explicar a Garcilaso como la base de una poética culta castellana. Inevitablemente el proyecto se somete a los moldes de la tradición humanística, ese sólido bloque de autores que funde la antigüedad y la época moderna como una unidad atemporal. No otra cosa hace Escalígero en la historia de la literatura del Hipercriticus ${ }^{31}$. Es una tradición inmensa que modeliza la poesía garcilasiana en el comentario de Herrera. Las fuentes y pasajes paralelos que se presentan en las Anotaciones nos lo muestran. En muchísimos casos Herrera no cita un pasaje por ser "fuente" de Garcilaso, sino porque en él se trata el mismo tema. La literatura, para Herrera, al igual que para Escalígero, forma una segunda naturaleza, más importante que la realidad inmediata o primera naturaleza ${ }^{32}$. Por eso Herrera cita textos paralelos: para que se confronten con los de Garcilaso y formen con ellos una unidad de materia de imitación y creación. Así, después del correspondiente verso de Garcilaso, podemos encontrar entrelazados ejemplos de Virgilio y Fracastoro, u Horacio y Pontano. La literatura antigua y neolatina enlaza con la poesía de Garcilaso formando una unidad de modelos egregios.

La nueva poesía, al pretender un lugar en el espacio cultural, tenía que ser un instrumento equiparable, aunque no igual, al verso latino, y debía conformarse a los mismos principios estéticos ${ }^{33}$. Por eso Herrera rompe con todo lo que estorba esa modelización. Por eso rechaza (cf. supra, p. 343) a Girolamo Ruscelli, Del modo di comporre in versi nella lingua italiana (1559), que le podría haber of recido una teoría sobre las cesuras y acentos junto con un afrentoso diccionario de rimas. Por eso también, las observaciones que hace sobre el hendecasílabo van en la misma línea que las de Pontano, y olvida, o pone en segundo plano, los acentos, el número de sílabas y la rima. Concuerda por otra parte con las actitudes dominantes del humanismo ante el estilo: preponderancia

3 Para Escalígero, la poesía antigua tiene un ciclo vital (infamia, adolescentia, iuventus, etc.) que acaba con Sidonio Apolinar y Boecio; un nuevo ciclo se inicia con Petrarca y llega a su madurez con Fracastoro, Pontano, etc. Cf. W. Ludwig, "Julius Caesar Scaligers Kanon neulateinischer Dichter", $A A b, 25$ (1979), 20-40.

${ }^{32}$ Cf. E. Dolce, "Note sul libro IV dei Poetices libri septem di G. C. Scaligero", Aevum, 48 (1974), 531-534.

33 Desde la óptica del verso agudo lo señala muy bien F. Rıco, art. cit., p. 16: “El «nuevo estilo $\gg$... no se contentaba con temas y tonos: aspiraba esencialmente a elaborar una poesía romance moldeada sobre los recursos más sutiles de la poesía clásica, a a propiarse la estructura del verso y del poema antiguos". El italianismo es no solamente una semántica nueva, sino también una poética nueva, con todas sus facetas. 
de la elocutio sobre la inventio y la compositio ${ }^{34}$. Aunque tiene finas observaciones sobre la construcción del poema ${ }^{35}$, en realidad ése es un punto secundario en su poética.

Herrera se separa, sin embargo, de una parte de la tradición humanística anterior, y especialmente de las opiniones y actitudes de los humanistas hispanos ante la literatura vulgar. Aunque al poco tiempo de publicarse la obra de Garcilaso (1543) algunos humanistas empiezan a señalarlo como el "modelo" del verso castellano --pienso concretamente en Ambrosio de Morales ${ }^{36}$-, una importante corriente del humanismo español, incluso después de 1550 , sigue con sus gustos arcaizantes y continúa considerando fundamental la literatura del siglo Xv: las "coplas" de Jorge Manrique, Juan de Mena, Ausias March, el Santillana de los Proverbios, etc. ${ }^{37}$ Esta línea, que se inicia con el "menismo" de Nebrija y Hernán Núñez y llega hasta gentes como el helenista Luis Pérez o Argote de Molina ${ }^{38}$, atiende más a los

${ }^{34} \mathrm{Cf}$. A Scaglione, The classical theory of composition, from its origins to the present: A historical survey, Chapel Hill, 1972, pp. 121 y 140.

${ }^{35} \mathrm{Cf}$. S. Ghertman, Petrarch and Garcilaso: $A$ linguistic approach to style, London, 1975, p. 130.

${ }^{36}$ Ambrosio de Morales, "Discurso sobre la lengua castellana" (1546), en V. SCORPIONi, "Il Discurso sobre la lengua castellana di Ambrosio de Morales: un problema di coerenza", StI, 1977 (Pisa), p. 187. También Álvar Gómez de Castro, en el mismo ambiente y actitudes que Morales, alude seguramente a Garcilaso en su "Comendación de las glossas vulgares": cf. "Tendences et caractéristiques de la poésie hispano-latine de la Renaissance”, en A. Redondo(éd.) L'humanisme dans les lettres espagnoles. XIX $X^{e}$ Colloque International d'Études Humanistes, Tours 5-17 Juillet 1976, Paris, 1979, pp. 136-137.

3) Son éstos los poetas que los humanistas citan o comentan: Mena es comentado por el Pinciano, con varias ediciones desde la sevillana de 1499, y alabado encarecidamente por Gonzalo Argote de Molina, en su Discurso sobre la poesia castellana, ed. E. F. Tiscornia, Madrid, 1926, pp. 44-45; Santillana es alabado como autor de los Proverbios por Juan Angel González en el Tragitriumpho, Valencia, 1524, fol. D2 v ${ }^{0}$; naturalmente es la obra de Santillana que más veces se imprimió durante el Renacimiento (cf. R. LAPESA, La obra literaria del Marqués de Santillana, Madrid, 1957, p. 281); Juan Hurtado de Mendoza traduce al latín las Coplas de Manrique (cf. D. Alonso, Dos españoles del Siglo de Oro, Madrid, 1960, pp. 66-68) y, después, Luis Pérez, profesor de griego del Marqués de Mondéjar, escríbe la Glosa famosa sobre las Coplas de Jorge Manrique, Valladolid, 1563; Hernán RuIz de Villegas escribe un poema latino en alabanza de Ausias March, en sus Opera, Venecia, 1734, p. 194; Alfonso García Matamoros es más explícito: en su Apologia, ed. J. López de Toro, Madrid, 1943, pp. 222-225, acepta con reparos la poesía italianizante, mientras que al hablar de Juan de Mena, Manrique, Santillana, dice: "A mí me parece que son los pregoneros de la riqueza y amplitud de la lengua española, los que en esta clase de rimas compusieron las más bellas fábulas y los más provechosos preceptos morales".

${ }^{38}$ Sobre la valoración de Mena en Nebrija véase Lore Terracini, Tradizione illustre e lingua letteraria nella Spagna del Rinascimiento, Roma, s.a., pp. 72-73: "Il «menismo $\gg$, se cosí si puè dire, di Nebrija e di Juan dei Encina non è il petrarchismo, italiano e spagnolo, del Cinquecento, e neppure il garcilasismo di Herrera. L'esemplarità che entrambi assegnano a Juan de Mena non deriva dall'idea di un'altezza poetica individuale, non più raggiunta, dalla quale estrarre canoni per una perenne imitazione”. Y justamente ésa es la actitud que prevalece entre los humanistas. 
contenidos que a las formas. Puede apreciar el italianismo, pero no como la base de una poética nueva. Percibe la delicada imitación de los antiguos o la semántica nueva, pero no la textura verbal. Esta estimación corre paralela a la práctica y valoración de las coplas castellanas a lo largo de toda la segunda mitad del siglo xvi ${ }^{39}$. Sánchez de las Brozas representa bien esa línea. Comenta a Garcilaso y después a Juan de Mena sin marcar una diferencia tajante. El extremeño no busca poner de relieve una excelencia estilística única en Garcilaso. Es importante aclarar esto porque atañe muy directamente a Herrera.

Aunque la edición de Mena, que estaba acabada en 1579 , no se publica hasta 1582, dos años después de las Anotaciones, la postura de Sánchez sólo se entiende si se tienen en cuenta todos sus comentarios. Sánchez postula como modelos tanto a Garcilaso como a Mena: "Ansí que no hay razón de desechar a Juan de Mena porque en nuestra edad hayan salido otros de estilo muy diferente", dice en el prólogo ${ }^{40}$. Y en la carta de 1579 al editor dice: "pareciéndome que no es tan malo como algunos piensan, determiné, y no sin ser importunado, que anduviese en marca tan pequeña como Garci-Laso; y que se puedan encuadernar juntos" ". Sánchez, además, aplica un esquema humanístico: lo que Enio y Lucrecio son a Horacio y Virgilio, eso es Mena respecto a los modernos (léase Garcilaso). Es una postura ecléctica y anticiceronia$\mathrm{na}^{42}$. Y lo que representa Herrera es justamente, aunque con matices, un ciceronianismo como el de Bembo. En el momento en que escribía Herrera, lo que importaba era fijar una lengua culta, y el eclecticismo

39 Así lo señaló O. H. GreEN, "On the coplas castellanas in the Siglo de Oro: Chronological notes", en Homenaje al profesor Rodriguez Moñino, Madrid, 1966, t. 1, pp. 213-219.

${ }^{40}$ Las obras del famoso poeta Juan de Mena, corregidas y declaradas por el maestro Francisco Sánchez, catedrático de Prima de Retórica en la Universidad de Salamanca, Madrid, 1804, p. 8 de los preliminares, sin numerar.

41 B. J. Gallardo, Ensayo de una biblioteca española de libros raros y curiosos, t. 3.

42 En latín Sánchez adopta una inteligente postura ecléctica e independiente frente a ciceronianismo y anticiceronianismo. Admite ciertas innovaciones léxicas, con moderación y siempre que "cum aliqua praefatione temperetur" (De autoribus interpretandis sive de exercitatione praecepta, en sus Opera, ed. G. Mayans, Genevae, 1766, t. 2, p. 81); no admite, sin embargo, los neologismos de los "Theologis, Medicis, Philosophis nostri saeculi", ni los del "doctissimus Ludovicus Vives" en su Exercitatio linguae latinae, y precisa: "Nihil enim nunc bene dicitur latine nisi tantum illud quod in libris politioris latinitatis invenitur" (In Artem Poeticam Horatii Annotationes, Salmanticae, 1591, p. 8). Pero la mejor latinidad no es solamente el modelo único de Cicerón. La Minerva es más clarificadora en ese sentido. La la tinidad que más aprecia Sánchez es la del "aureum saeculum Ciceronis", naturalmente, pero en él se incluyen también Terencio y Salustio. Rechaza explícita mente la latinidad de Séneca, Plinio el joven y la del Digesto (III, 14; Lugduni, 1789, pp. 461-462); pero al mismo tiempo considera a Apuleyo "purissimus latinae linguae scriptor" (ibid., p. 469), cuando justamente la crítica a Apuleyo y al latín africano es uno de los caballos de batalla de los humanistas ciceronianos (NORDEN, Die antike Kunstprosa, t. 2, pp. 590-591). 
no ayudaba en nada. El ciceronianismo era una necesidad práctica ${ }^{43}$. Y aunque la postura del Brocense pueda parecernos más atractiva, la solución ciceroniana de Herrera era la más lúcida ${ }^{44}$.

Además, Sánchez se enfrenta a Herrera y a la codificación italianizante desde el ángulo del contenido. Por eso dice en el prólogo a su edición de Mena (p. 7, sin numerar): "Y al fin los que hallan este poeta por pesado son unos ingenios que ponen todo su estudio en hacer un soneto o canción de amores, que para entenderlos es menester primero preguntarles a ellos si lo entendieron". El contenido "serio" de Juan de Mena no puede compararse con la liviandad de los sonetistas que en última instancia pueden llegar a ser tan obscuros como el ilustre secretario real. Se trata de la vieja crítica moral del humanismo, como la que practican Vives, Arias Montano o Malón de Chaide contra los libros de caballerías y las Dianas. La poesía de fray Luis es un intento de dar respuesta a esta línea crítica del humanismo español.

En Herrera no se trata tampoco de un ciceronianismo riguroso, como tampoco lo es el del Bembo vulgar. Las Prose aceptan y sancionan el arcaísmo, y lo mismo hace Herrera. En esto coinciden los defensores de la lengua vulgar y el anticiceronianismo de Poliziano o Pontano. Se trata solamente de la tendencia a afirmar la excelencia de un modelo único, "alguna buena escritura, cuyo estilo o género de dezir pudiesse uno seguirlo para emendar su habla", como dice Ambrosio de Morales preludiando a Herrera.

Por otra parte, el Brocense sólo atiende en su comentario a la dependencia semántica de la memoria poética garcilasiana respecto a los antiguos ${ }^{45}$, y aplica un método de recensio y enarratio como lo podría hacer con un autor clásico. Evidentemente, es sólo una lectura parcial del texto. Herrera huye de ese callejón sin salida. Tiene que demostrar la excelencia de Garcilaso, y un comentario de tipo tradicional, por muy bien hecho que esté, no es la mejor manera. Debe rechazar el método de Sánchez, ignoránd olo explícitamente, y buscar un camino distinto. No puede actuar co mo filólogo de la lengua vulgar o como gramático, y por eso enlaza con el antinormatismo de Pontano ${ }^{46}$. Los mismos efectos que produce el verso clásico se pueden

${ }^{43}$ Así lo ha señalado C. Dı́nisotri, prólogo a las Prose e rime de Bembo, $2^{\mathrm{a}}$ ed., Torino, 1971, pp. 38-39 y 44-45.

${ }_{44}$ Sobre el ciceronianismo latino en España en la segunda mitad del siglo xvı véa se E. Asensio,"Ciceronianos contra erasmistas en España. Dos momentos (1528-1560)", $R L C, 52$ (1978), 135-154, especialmente pp. 153-154.

${ }^{45}$ Cf. E. Rivers, "L'humanisme linguistique et poétique dans les lettres espagnoles du $x^{e}{ }^{e}$ siècle" en A. Redondo (éd.), L'humanisme dans les lettres espagnoles, pp. $169-176$.

46 F. TAteo, "La Poetica di Giovanni Pontano", FR, 6(1959), 350 ss. Aunque en ese ámbito y en el campo de la búsqueda de imitaciones el comentario de Herrera es más rico que el del Brocense, como señala A. Alatorre, "Garcilaso, Herrera, Prete Jacopín y Don Tomás Tamayo de Vargas”, $M L N, 78$ (1963), 345-346. 
encontrar en Garcilaso. Es en este terreno donde Herrera puede lograr su objetivo y superar la miopía del humanismo coetáneo. Es en el campo de las observaciones estilísticas donde puede defenderse. Así, de la misma manera que el análisis empírico de Virgilio, a través de las páginas del Actius, barre con todo lo que digan los Servios y Donatos, de igual manera la realidad del verso de Garcilaso, en manos de Herrera, deja atrás al Brocense y sus acólitos.

Universidad Nacional Autónoma de México

Juan F. Alcina Rovira 